This item was submitted to Loughborough's Research Repository by the author.

Items in Figshare are protected by copyright, with all rights reserved, unless otherwise indicated.

\title{
Cement nanotubes: on chemical gardens and cement
}

PLEASE CITE THE PUBLISHED VERSION

http://dx.doi.org/10.1007/s11224-016-0811-0

\section{PUBLISHER}

(C) Springer

VERSION

AM (Accepted Manuscript)

\section{PUBLISHER STATEMENT}

This work is made available according to the conditions of the Creative Commons Attribution-NonCommercialNoDerivatives 4.0 International (CC BY-NC-ND 4.0) licence. Full details of this licence are available at: https://creativecommons.org/licenses/by-nc-nd/4.0/

\section{LICENCE}

CC BY-NC-ND 4.0

\section{REPOSITORY RECORD}

Cardoso, Silvana S.S., Julyan H.E. Cartwright, Oliver Steinbock, David A. Stone, and Noreen L. Thomas. 2016. "Cement Nanotubes: On Chemical Gardens and Cement". figshare. https://hdl.handle.net/2134/22582. 


\section{Cement nanotubes: on chemical gardens and cement}

Silvana S. S. Cardoso ${ }^{1}$, Julyan H. E. Cartwright ${ }^{2,3}$, Oliver Steinbock ${ }^{4}$, David A. Stone ${ }^{5}$, Noreen L. Thomas ${ }^{6}$

${ }^{1}$ Department of Chemical Engineering and Biotechnology, University of Cambridge, Cambridge CB2 3RA, UK

${ }^{2}$ Instituto Andaluz de Ciencias de la Tierra, CSIC-Universidad de Granada, E-18100 Armilla, Granada, Spain

${ }^{3}$ Instituto Carlos I de Física Teórica y Computacional, Universidad de Granada, E-18071 Granada, Spain

${ }^{4}$ Department of Chemistry and Biochemistry, Florida State University, Tallahassee, FL 32306-4390, USA

${ }^{5}$ Iron Shell LLC and Tohono O'odham Community College, Tucson, AZ 85717-1602, USA

${ }^{6}$ Department of Materials, Loughborough University, Loughborough LE11 3TU, UK

"Do cement nanotubes exist?" is a question that has recently been asked. The answer is yes, they do exist. The evidence is in the literature, in tens of papers showing in detail chemical-garden type tubes in cement from the nanoscale upwards that were published in the 1970s and 1980s. Here we present a nano-review of the literature.

Here is a curious case of lack of continuity in the materials field. Out of the great amount of work on cement nanotubes (see Figure 1) performed in the 1970 s and $1980 \mathrm{~s}^{[1-8]}$, and even extending to the end of the $1990 \mathrm{~s}^{[9,10]}$ one of the outstanding, high-impact, publications is a 1976 paper in Nature by Double and Hellawell ${ }^{[1]}$ that makes a direct comparison between chemical gardens and the "fibrillar" formations they observed (with electron microscopy) around hydrating cement particles. When we checked, it had been cited 45 times, but most of the modern cites are by researchers studying self-assembled tubular precipitation structures associated with chemical gardens ${ }^{[11-14]}$, while the cement researchers themselves seem to have forgotten about these studies. For example, consider the recent article in Advanced Materials by a Hispano-German team entitled, "Do cement nanotubes exist?" $[15]$ They propose that inorganic nanotubes made of cement minerals like calcium silicate hydrate would make excellent reinforcement of the matrix, even better than carbon fibres, which are hydrophobic. Using density functional tight-binding theory and other models they simulate the formation, characteristics, and function of nanotubes. They conclude that they have "opened up a new area of research" by proposing the synthesis of such nanotubes. Not only do they not refer to the Double and Hellawell article, they declare that "a successful synthesis of portlandite and tobermite C-S-H (Calcium Silicate Hydrate) based inorganic nanotubes has yet to be devised by inorganic chemists." It is true that Double and others did not provide a complete crystallographic characterization of cement tubes. Yet the 1976 Nature paper was no fluke: not just one group but several working back then wrote tens of papers showing in detail the formation of tubes in cement. The question then became one of establishing to what measure the mechanism of production of hollow tubules in cement can be connected to that of traditional chemicalgarden type tubes; a question asked by Alan Mackay in $1980^{[6]}$ that remains open, and one that interdisciplinary research between the field of chemobrionics ${ }^{[11-14]}$ and that of cement research could resolve. 
It is a great pity, then, that this work has been forgotten by the field. A recent cement review reports: "During the 1980s, several papers reported that specific morphological features seem to form during each stage of reaction. The $\mathrm{C}-\mathrm{S}-\mathrm{H}$ needle morphology that typically forms preferentially during the early stages was once seen as a clue to the reaction mechanism, but this has not stood the test of time." ${ }^{[16]}$ It is unclear to us what test Time has carried out in this instance, but the literature clearly establishes the existence of cement nanotubes.

The word cement is loosely defined because it just means a binder for sticking things together. For example, the Romans had their own version, which was a mixture of wet lime and pozzolanic ash. However, we focus on OPC (Ordinary Portland Cement), which does have a (reasonably) well-defined composition. The connection between Portland cement hydration and chemical gardens is that the major product of cement hydration is $\mathrm{C}-\mathrm{S}-\mathrm{H}$ gel, which is amorphous and acts as a semi-permeable membrane. Hence it was proposed that C-S-H gel coatings rupture under osmotic pressure and produce tubular growths comparable to chemical gardens.

We show in Fig. 2 an image from a paper by David Double ${ }^{[17]}$ from 1978 showing tubular growths formed during the hydration of Portland cement. These micrographs were taken in an environmental cell (i.e., wet cement) in a high-voltage transmission electron microscope. Also included in this paper are micrographs showing fibres growing during the in-situ hydration of alite (i.e., pure tricalcium silicate, $\mathrm{C}_{3} \mathrm{~S}$ ), which is the main constituent of Portland cement. The images are very impressive evidence for hollow tubes.

In a recent paper by Fonseca and Jennings ${ }^{[18]}$ about the fibrillar morphology of C-S-H formed in $\mathrm{C}_{3} \mathrm{~S}$ systems, the authors claim that the drying method influences the length and width of the fibrils, which ranges from 10-300 nm (compatible with Fig. 4 of Double's paper). However, they don't confirm whether the fibrils are hollow or not. Double's Fig 2 is very impressive; Fonseca and Jennings's pictures are not completely clear on this point, but it is possible that their structures could be both hollow and closed, if they were formed by tubes that tapered off and became capped as the flow within them diminished and ceased.

There can be other growths in OPC systems that look like needles, which are not produced by an osmotic mechanism and are therefore not tubular growths like chemical gardens. Here we are referring to ettringite, which is a calcium alumino-sulphate hydrate, and grows by a conventional crystallization and growth mechanism. It is present because of the addition of gypsum (calcium sulphate), which is added in small amounts to prevent flash setting of the aluminate phases. Ettringite needles have a hexagonal cross-section, and are obviously chemically very different from C-S-H gel. Also they form at a different time during the hydration process (etttringite at the start and $\mathrm{CSH}$ tubes much later). $\mathrm{A}$ further point is that ettringite should be present in a small amount — it comes from gypsum, which is a minor component of the cement - and may not be present at all.

Regarding the size of the tubes in a situation like chemical gardens (i.e., considering the densities and pressures etc that are reasonable), the $Q \sim 1 / R^{\wedge} 4$ dependence (HagenPoiseuille law) limits flow for the typical pressures generated by osmosis in these systems. One of the few quantitative studies on tube radii of chemical gardens was published by the Steinbock group, but it does not establish a lower limit. Flow out of the tube competes with diffusion. If the flow is too slow, (say less than a micrometer?) diffusion fluxes will cap/plug the tube. This may be what is occurring in these cement systems, e.g., in Fig 1. We estimate the capping time as $t_{c}=a^{2} / D$, where $a$ is the tube radius and $D$ is the typical 
molecular diffusivity of an ion in a liquid. The typical time for motion of the liquid by a distance $a$ is $t_{m}=a / u$, where $u$ is the speed of the liquid. In Figure 3 , we compare the predicted capping time with the motion time, over a range of tube radii for fluid speeds of 0.01 and $0.02 \mathrm{~m} / \mathrm{s}$. We expect some capped and some hollow tubes of radii of $50 \mathrm{~nm}$, as observed in Figure 2, to be present when the fluid speed is $\sim 0.02 \mathrm{~m} / \mathrm{s}$; for lower speeds capped tubes will be favoured. We thus conclude that fluid in cement may move, owing to osmotic and other forces, with speeds of a few centimetres per second. Laboratory experiments with chemical gardens [19] have shown that the ratio of the fluid speed and the tube growth-rate can be as high as few hundred. The photograph in Figure 2 suggests a tube growth rate of approximately $2 \times 10^{-4} \mathrm{~m} / \mathrm{s}$. This value is approximately a hundred times smaller than the predicted fluid speed, confirming that our estimates are physically acceptable. A fluid speed of $\sim 0.02 \mathrm{~m} / \mathrm{s}$ in a tube of length $2000 \mathrm{~nm}$, as observed in Figure 2 , would require a driving pressure of $\sim 10^{4} \mathrm{~Pa}$.

To return to chemical gardens, the authors of the review paper [16] dismissive of the work on C-S-H fibre morphology carried out in the 1980's, report that the cement hydration mechanism most consistent with direct experimental evidence (from nuclear resonance reaction analysis) involves rupture of a semipermeable C-S-H barrier layer. They assert that this rupture process is due to the build-up of osmotic pressure and allows trapped silicate ions to come into contact and react with the calcium-rich solution. This mechanism has all the hall-marks of an osmotic pumping model and a reverse silicate garden.

In addition, the chemical garden mechanism explains a connection with corrosion phenomena in that steel immersed in potassium ferrocyanide solution can also produce an amorphous semi-permeable reaction product of ferri-ferrocyanide capable of growing tubular morphologies. Hence when amorphous semi-permeable membranes are produced, there will be a connection between cement hydration mechanisms and corrosion phenomena. In work [20] investigating reagents for accelerating cement hydration for use with reinforced concrete, a striking similarity has been discovered between ions that accelerate cement hydration and those that cause corrosion of steel, and also a similarity between those that retard cement hydration and those that inhibit corrosion. Finally, in an electrochemical corrosion cell containing an iron salt solution and augmented by direct current it has been shown that a variety of hollow structures of iron oxides ranging from closed 'tubercles' to open tubes readily form on the surface of the negative electrode [14]. This pattern points out the similarity between the mechanisms of cement hydration and the corrosion of steel.

It is clear that some important questions about cement hydration remain unanswered. These include the mechanism controlling the beginning of the acceleration stage, growth processes governing the morphologies of the hydration products and the mechanisms influencing cement hydration accelerators and retarders [16]. Following the activity in the 1970's and 1980's, there has been little application of the ideas of chemical-gardens to cement hydration. With modern analytical techniques and fresh insights, much progress could be made.

It appears that one fundamental difference between the research on the products of cement hydration and those of chemical gardens is that the former have been passively observed while the latter have been mostly actively created by investigators. The focus of cement researchers is, understandably, on the structural behavior of Portland cement for construction applications. Scientists studying chemical gardens, on the other hand, are primarily concerned with the specific mechanisms producing the intriguing tubular growth out of purely scientific curiosity and apart from practical applications. This research 
community readily shares its ever-growing array of methods for growing the tubular structures with an emphasis on continuously elucidating every chemical and physical aspect of the growth process. Perhaps a way to build a bridge between the two research communities would be to apply the approach of the chemical garden researchers to the process of cement hydration. This would mean setting up an experimental cell using the components of cement paste but where free boundary conditions exist. The water-filled interstitial space within the paste must be opened up so that such structures could grow unimpeded out into an aqueous solution exposed to view. Indeed, this is what Double and Hellawell [1] were investigating in their cement hydration experiments using an environmental cell in a high voltage transmission electron microscope.

It is time to take another look and try to settle this issue. We would like to determine the conditions necessary for the appearance of $\mathrm{C}-\mathrm{S}-\mathrm{H}$ fibrils and then to augment those conditions so that we can focus on explicating the growth mechanisms. It is a different approach from the traditional study of cement but we would hope that by isolating this one phenomenon we can both answer some specific questions about the structures themselves as well as make some observations relevant to the use of concrete for construction. We propose such work here in the hope that this odd disconnect within materials research might be supplanted with a healthy exchange between researchers who seem to share mutual interests.

\section{References}

[1] D. D. Double and A. Hellawell, "The hydration of Portland cement" Nature 1976, $261,486$.

[2] D. D. Double and A. Hellawell, "The solidification of cement" Scientific American 1977, 237, 82.

[3] D. D. Double, A. Hellawell and S. J. Perry, "The hydration of Portland cement" Proc. Roy. Soc. A 1978, 359, 435-451.

[4] J. D. Birchall, A. J. Howard and J. E. Bailey, "On the hydration of Portland cement" Proc. Roy. Soc. A 1978, 360, 445-453.

[5] H. M. Jennings and P. L. Pratt, "An experimental argument for the existence of a protective membrane surrounding Portland cement during the induction period", Cement and Concrete Research 1979, 9, 501-506.

[6] P. Barnes, A. Ghose, and A.L. Mackay, "Cement tubules - another look", Cement and Concrete Research 1980, 10, 639-645.

[7] D. D. Double, "New developments in understanding the chemistry of cement" Phil. Trans. Roy. Soc. A 1983, 310, 53-66.

[8] D. D. Lasic, M. M. Pintar and R. Blinc, "Are proton NMR observations supportive of the osmotic model of cement hydration?" Phil. Mag. Lett. 1988, 58, 227-232.

[9] L. D. Mitchell, M. Prica and J. D. Birchall, "Aspects of Portland cement hydration studied using atomic force microscopy" J. Materials Sci. 1996, 31, 4207-4212.

[10] S. M. Clark, G. R. Morrison, and W. D. Shib, "The use of scanning transmission Xray microscopy for the real-time study of cement hydration" Cement and Concrete Research 1999, 29, 1099-1102.

[11] L.M. Barge, S.S.S. Cardoso, J.H.E. Cartwright, G.J.T. Cooper, L. Cronin, A. De Wit, I.J. Doloboff, B. Escribano, R.E. Goldstein, F. Haudin, D.E.H. Jones, A.L. Mackay, J. Maselko, J.J. Pagano, J. Pantaleone, M.J. Russell, C.I. Sainz-Díaz, O. Steinbock, D.A. Stone, Y. Tanimoto, N.L. Thomas, From chemical gardens to chemobrionics, Chem. Rev. 2015, 115, 8652-8703. 
[12] J. H. E. Cartwright, J. M. García-Ruiz, M. L. Novella, and F. Otálora, "Formation of chemical gardens" J. Colloid Interface Sci. 2002, 256, 351-359.

[13] S. Thouvenel-Romans and O. Steinbock, "Oscillatory growth of silica tubes in chemical gardens", J. Am. Chem. Soc. 2003, 125, 4338-41.

[14] D. A. Stone and R. E. Goldstein, "Tubular precipitation and redox gradients on a bubbling template", Proc. Natl Acad. Sci. USA 2004, 101, 11537-11541.

[15] H. Manzano, A. N. Enyashin, J. S. Dolado, A. Ayuela, J. Frenzel, and G. Seifert, "Do cement nanotubes exist?" Adv. Mat. 2012, 24, 3239.

[16] J. W. Bullard, H. M. Jennings, R. A. Livingston, A. Nonat, G. W. Scherer, J. S. Schweitzer, K. L. Scrivener, and J. J. Thomas, "Mechanisms of cement hydration" Cement and Concrete Research 2011, 41,1208-1223.

[17] D. D. Double, "An examination of the hydration of Portland cement by electron microscopy", Silicates Industriels 1978, 11, 233-246.

[18] P. C. Fonseca, H. M. Jennings, "The effect of drying on early-age morphology of CS-H as observed in environmental SEM", Cement and Concrete Research 2010, 40, 1673-1680.

[19] D. A. Stone, B. Lewellyn, J. C. Baygents, and R. E. Goldstein "Precipitative Growth Templated by a Fluid Jet" Langmuir 2005, 21, 10916-10919.

[20] N. L. Thomas, "Corrosion problems in reinforced concrete: why accelerators of cement hydration usually promote corrosion of steel", J. Mater. Sci, 1987, 22, 3328-3334. 

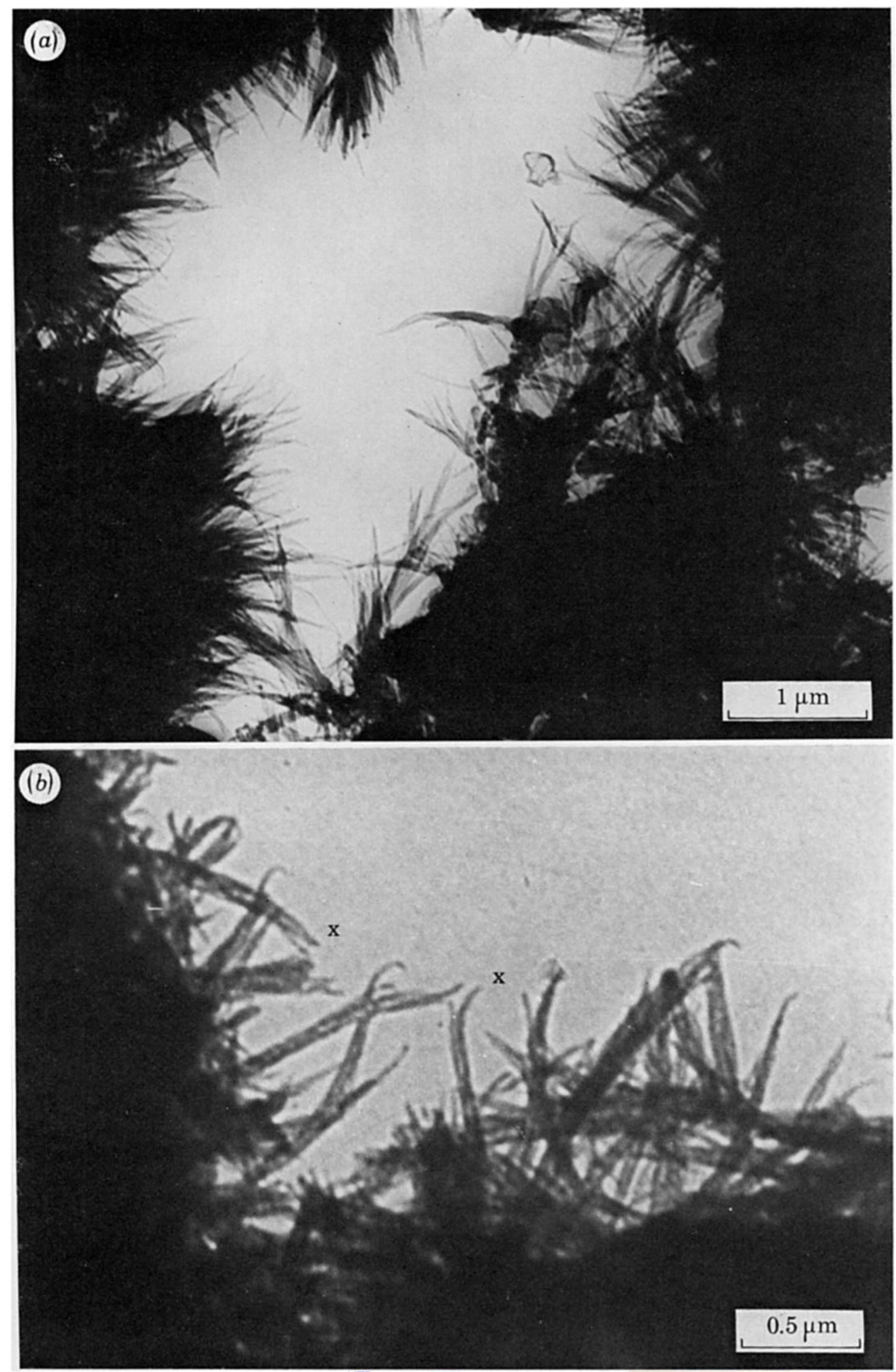

Figure 1: Cement tubes: (a) Cement + water sample after more than 1 day showing the secondary fibrillar development of C-S-H gel around the cement grains. (b) Greater detail of fibres. Environmental specimen stage, high voltage electron microscope. From Double et al., [4]. 


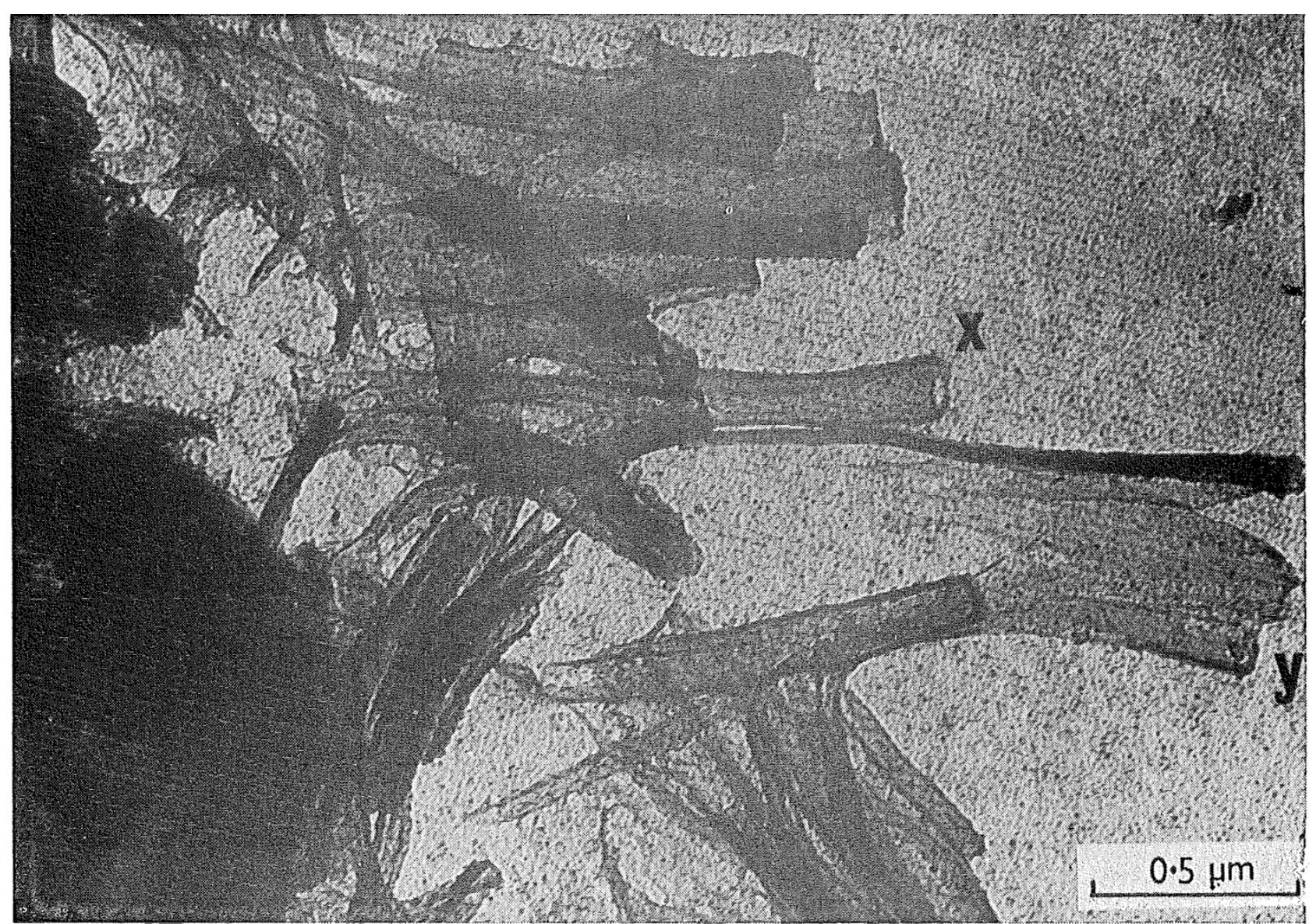

Figure 2: Dried cement sample showing fibrillar C-S-H hyration product, the appearance of which suggests tubular morphologies. Transmission electron micrograph. From Double [17]

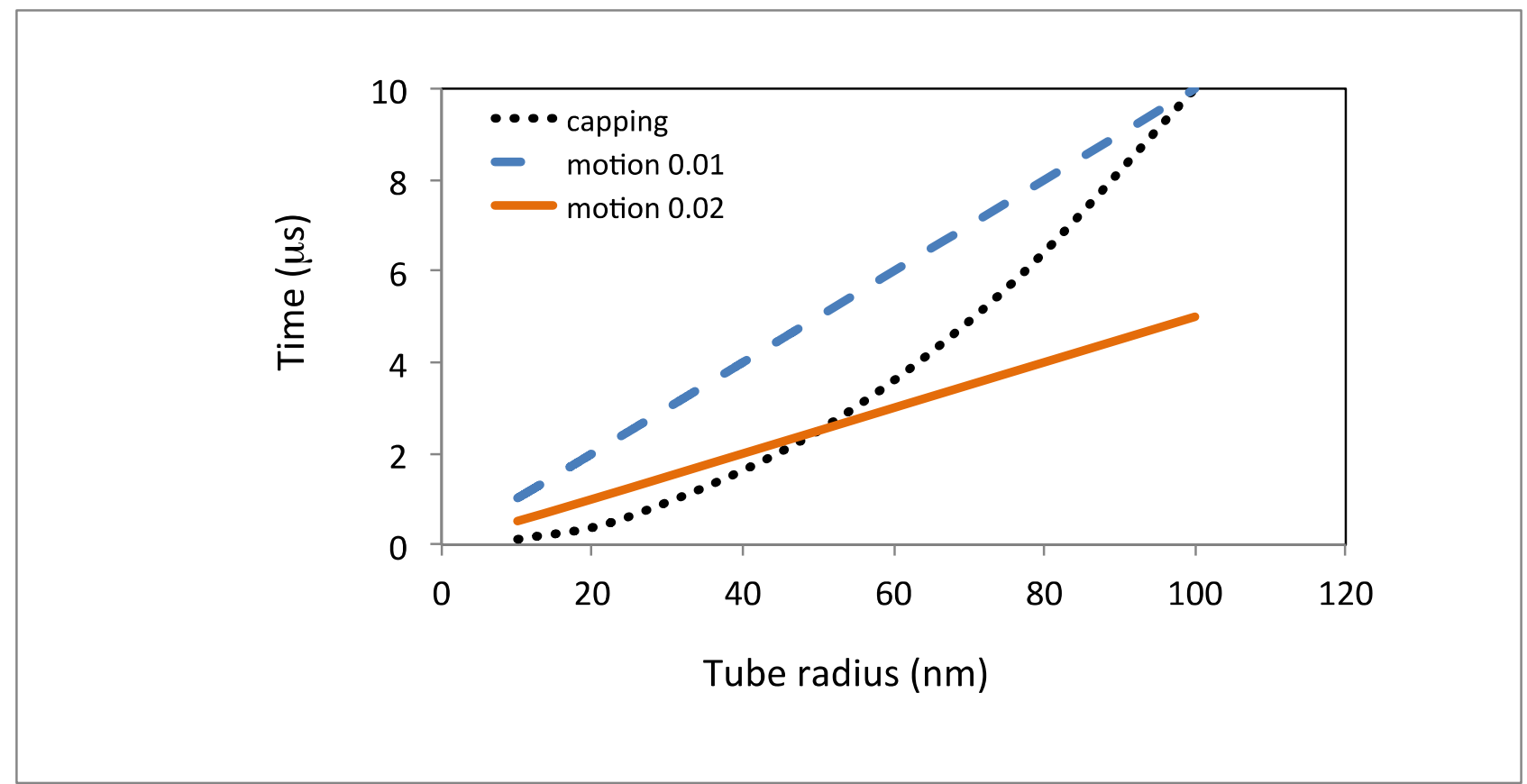

Figure 3: Comparison of predicted capping and fluid motion times over a range of tube radii for fluid speeds of 0.01 and $0.02 \mathrm{~m} / \mathrm{s}$. Capped tubes prevail over hollow ones for low fluid speeds and small tube radii. 